\title{
Divorce and the Duality of Marital Payoff
}

\author{
Pierre-André Chiappori* \\ Natalia Radchenko ${ }^{\dagger}$ \\ Bernard Salanié
}

May 23, 2016

\begin{abstract}
Empirical studies on the determinants of divorce are scarce in economics. One reason is the duality of the value of marriage, which combines economic gains for which proxies can be found and non-pecuniary gains that are much harder to measure. The literature on marital stability has therefore focused on the impact of income differentials between partners, omitting shocks to the non-economic components of the value of the marriage. We fill in the gap by extending the model of marriage dissolution to account for a time-varying non-pecuniary quality of the match. To explore its importance, we exploit a unique data set from the Russia Longitudinal Monitoring Survey (RLMS) which provides both labor market outcomes of the couples and subjective well-being data. Our results suggest that the monetary and non-monetary components enter the joint surplus additively, with gender-specific marginal rates of substitution. The valuation of the monetary components also reveal gender asymmetry, which we link to differences in remarriage prospects.
\end{abstract}

Keywords: matching, marriage, divorce.

JEL codes: J12, D1

\footnotetext{
${ }^{*}$ Columbia University.

${ }^{\dagger}$ American University, Washington DC.

${ }^{\ddagger}$ Columbia University.
} 


\section{Introduction}

A growing body of empirical literature has studied family formation and its close relationship to fundamental questions of household and labor economics. These include the market and domestic labor supply of spouses, their consumption of individual and public goods, transfers between spouses and children, family welfare, and the intrahousehold allocation of resources (Browning, Chiappori and Weiss 2014 offer a detailed and comprehensive overview of recent advances in the field.) In contrast, Charles and Stephens (2004) point out the scarcity of empirical studies on the determinants of marital dissolution and their links to household and labor economics. Ten years later, this statement is still accurate, even though the theory of marital stability and dissolution started with Becker, Landes and Michael (1977) (see Becker 1991 for a view of early contributions.)

The starting point of the divorce theory is a welfare analysis based on comparing individual utilities from remaining married and from divorcing. Divorce occurs endogenously whenever the former drops below the latter for one partner, possibly after reallocation of the surplus within the couple. Utilities in marriage combine two components: an economic gain that comes from public goods, risk-sharing, intertemporal consumption smoothing, and intrahousehold transfers; and non-pecuniary gains pertaining to spouses' love, intensity of the initial connection, complicity and companionship (Browning et al., 2014). Both components may evolve over time in response to new information that married persons receive about themselves and their partners.

Since the noneconomic benefits to marriage are problematic to measure, starting with Becker, Landes and Michael (1977) empirical work has focused on the impact of income variations on the probability of divorce using various sets of (mostly) US and UK data. Hoffman and Duncan (1995) found weak effects of economic factors on the divorce hazard on 1968-87 PSID data. Weiss and Willis (1997) exploited panel data from the NLSY to study the role of earning "surprises" (changes in long-run predictions of earnings at different periods of marriage) in marital dissolution. Their results showed that predictions of earnings at the time of marriage did not explain marriage patterns (conditional on education, religion and ethnicity). However, unexpected changes in earnings were strong determinants of the hazard of divorce. Using UK data (BHPS), Böheim and Ermisch (2001) found that couples experiencing unexpected improvements in finances have lower dissolution risk, while couples experiencing negative shocks are at higher risk.

Hess (2004) also used the NLSY; he concluded that divorce is more likely when income shocks

of the partners are positively correlated, and when one partner has a more volatile income 
process than the other. He also used a model of marriage to derive testable restrictions in terms of spouses' income correlation and marriage duration. His tests suggest that the non-pecuniary benefits to marriage are not a substitute to its economic benefits.

Other work has distinguished income- and wealth-related shocks by their nature. Charles and Stephens (2004) explicitly model earning shocks as due to job loss or disability. Using US data (PSID), they find that job displacement increases the divorce hazard, but disability does not. They argue that this shows that divorce decisions are also driven by non-pecuniary factors. Rainer and Smith (2010) use UK data (BHPS, 1991-2004) and study the impact of housing price shocks. They find that the hazard of divorce increases after negative price shocks, while positive shocks have little effect. The responses are quite heterogeneous: they depend on homeowner/renter status as well as cohorts and couples at different levels of income and mortgage debt. Battu, Brown and Costa-Gomes (2013) extend the exploration of financial shocks on marriage dissolution. They confirm that negative financial shocks make divorce more likely. On the other hand, a negative shock from non-labor income has no impact, while a positive one increases the dissolution hazard. They do not find a significant impact of housing price shocks.

This brief review shows that the literature exploring marital stability focused on the impact of income differentials and shocks to earnings and wealth. Much less has been done to take into account the non-economic components of the value of the marriage. Weiss and Willis (1997) try to control for it using self-reported happiness during first five years of marriage. Otherwise, the quality of match is usually modeled using fixed effects, which implies that the value of marriage is time-invariant in terms of its non-pecuniary traits (for example Charles and Stephens, 2004; Nunley and Seals, 2010). To the best of our knowledge, no empirical work allows for shocks to the non-pecuniary quality of the match.

The happiness literature has studied the relationship between marital status and subjective well-being (for example Gardner and Oswald, 2006; Lucas, Clark, Georgellis and Diener, 2003; Waite and Gallagher 2000). But its goal is to evaluate the effect of marital status on the happiness of individuals, while we are interested in the reverse link. The majority of the studies focus on comparing reported levels of subjective well-being across different individuals. It reports a positive association between marriage and subjective well-being. Economic demographers and psychologists relate this correlation to selection effects, social roles effects, and adaptation. The selection hypothesis implies that happier people are more outgoing and are more successful in finding a good match, while unhappy people are more likely to have trouble finding a stable mate. The social role hypothesis implies that divorced 
individuals are less likely to have social networks and more likely to have financial difficulties. Lucas et al. (2003) focus on the marriage of German couples and conclude that there is a short-term relationship between one's changes in subjective well-being and marital status transitions to married, divorced or widowed. To explain this, they put forward the idea of adaptation, wherein subjective well-being reacts to events such as changes in marital status but returns to baseline level of satisfaction. Within the discussion, Lucas et al.(2003) ignore the gain from marriage and its evolution. Lastly, Bruze, Svarer and Weiss (2015) estimate a dynamic model of marriage, divorce and remarriage using panel data on two cohorts of Danish men and women, in which the marital surplus is identified from the probability of divorce.

Among very few works relating subjective well-being to the probability of divorce are the studies by Gardner and Oswald (2006), Lundberg (2012), and Guven, Senik and Holger (2012). Using British data, Gardner and Oswald (2006) find that couples breaking up are initially less happy than the norm in the population, and that they eventually experience positive shocks in life satisfaction after divorce. Lundberg finds an impact of some personality traits, such as emotional instability, extraversion, etc. on marital dissolution. Guven et al. explore the impact of spouses' differences in subjective well-being on the probability of divorce using German, British, and Australian data. These differences are shown to be positively correlated with the divorce hazard. The authors interpret this finding as evidence for an aversion to unequal intrahousehold distributions of well-being. They also run a number of tests to provide empirical evidence against reverse causality - the hypothesis that expectations of an impending break-up induce a happiness gap between spouses. More specifically, they show that the happiness gap has a significant impact even in the first year of marriage, and the correlation under question is unrelated to post-divorce perspectives. Guven et al. (2012) document gender asymmetry: the effect of the well-being gap is driven by unhappier women. They also find that it is larger among couples where women earn high income and/or men are unemployed.

Once again, this literature does not allow for shocks to non-pecuniary benefits of marriage over time. Moreover, the two strands of literature have not merged: one focuses on economic benefits, the other does on non-pecuniary benefits. We fill in these two gaps using an integrated framework in which gains from marriage have both monetary and non-monetary time-varying components. To do this, we exploit a unique data set coming from the Russian Longitudinal Monetary survey (RLMS), which provides detailed information on households over the period of 1994-2013. In addition to standard information on demographic characteristics and earnings of individuals, it contains subjective data on satisfaction with life. 
This allows us to link shocks to the subjective well-being (conditioned on other, "economic" shocks) with the evolving quality of the match.

Our results suggest that monetary and non-monetary ingredients combine additively in joint marital output. Non-monetary satisfaction impacts marital stability positively, and matters more for women than for men. The results related to the monetary components reveal also gender asymmetry, which can be explained by differences in probability of remarrying. They call for a more dynamic view of matching and rematching.

The paper is organized as follows. Section 2 outlines the conceptual framework of marital outcome, monetary and non-monetary components of the gain from marriage and spouses' divorce decision. We describe how we use the ongoing annual panel Russia Longitudinal Monitoring Survey (RLMS) in section 3. Section 4 analyzes the subjective self-reports. Section 5 describes our empirical approach to the determinants of the divorce hazard. Section 6 presents the results.

\section{Theoretical Background}

A vast body of theoretical literature has been devoted to marriage formation and dissolution. ${ }^{1}$ The main conclusions can be summarized as follows.

Efficient divorce First and foremost, divorce typically is a joint decision that involves renegociations and transfers. Even when unilateral, divorce does not necessarily happens when one partner is no longer satisfied with the relationship; separation occurs only if all possible renegotiations have been unsuccessfully explored, that is in the event of inachiavable (re)allocation of resources within the household such that both spouses would find continuation of marriage better than divorce. This intuition, initially introduced by Becker (1973, 1974), is central to our current understanding of the phenomenon. It implies that one may think of divorce as an efficient phenomenon; divorce occurs when no renegotiated agreement could make the continuation of marriage a valid alternative for both spouses. If for instance a negative shock affects the non monetary component of the marital gain, divorce can be seen as an opportunity to "resample"; it therefore has an option value (Chiappori and Weiss 2006, 2007).

\footnotetext{
${ }^{1}$ See Becker (1991) for an early survey, and Browning et al. (2014) for a more recent presentation.
} 
A specific version of this argument, emphasized by Becker (1973), further assumes that utilities are transferable within the household, both while married and after divorce. To be more precise, there exist cardinal representations of each spouse's preferences such that the utility frontier is a straight line with slope -1 , irrespective of prices and incomes. In practice, this assumes that individuals can transfer utility between them at a constant "exchange rate". In this context, one can derive the well-known "Becker-Coase theorem", which states that laws governing divorce (mutual consent versus unilateral, as well as division of resources and definition of alimony payments) cannot influence the divorce rate. However, the necessary conditions for this conclusion to hold are strong and quite unlikely to hold in practice, as argued by Chiappori, Iyigun and Weiss (2015).

Non economic gains from marriage Secondly, the gain from marriage depends on both economic and non economic components; shocks affecting any of these components may trigger either renegotiation or divorce. Non monetary components of marital gain are usually modeled as random factors drawn from some exogenous distribution, that enter utility additively; as we shall see, this form fits our empirical findings quite well. Simple as it may seem, such a setting allows for rich interactions between the various components; for instance, a negative shock affecting the non economic component may or may not be compensated by renegotiated utility transfers between spouses, depending on the magnitude of economic gains.

Technically, part of the literature assumes that non economic effects can be summarized by a single indicator which is common to both spouses. This is often called the "quality of the match". Other contributions introduce individual-specific shocks. The distinction is partly related to different theoretical backgrounds; for instance, under transferable utility (TU), individuals may value differently the non-monetary aspects of the relationship but only the sum of their evaluations matters. Our data allow us to reconsider this issue from a novel perspective. First, we show that individual evaluations, although correlated, do not coincide. Second, and in sharp contrast with the predictions stemming from a TU model with additive shocks, the impact of individual evaluations is not symmetric across genders. Our findings therefore provide new insights into the issue.

Economic gains from marriage Economic gains from marriage can be classified into two main categories. Some are related to the existence of economies of scale or public consumptions, which a larger household obtains more efficiently. Many authors include fertility within this category: to the extent that children's well-being enters both parents' 
utilities, they are indeed publicly consumed. Households can also be viewed as "clubs" that alleviate some market incompleteness or failures. For instance, in the absence of a complete set of financial markets, individuals within a household can share risk in a mutually beneficial way. Similarly, coordinating labor supply may help cope with liquidity constraints and restore efficient investments, particularly in human capital (one may think of the cliché story of the wife working as a nurse while the husband studies medicine).

Clearly, analyzing the economic gains to marriage raises difficult issues, related in particular to the notion of commitment. Risk sharing and coordinated savings obviously require the ability to commit to some future behavior. Risk can be shared only if each spouse can commit to transfer part of his or her income to a less-lucky partner; a nurse for instance would be reluctant to fund her husband's training if she believed that he would leave her after his graduation. It is fair to say that no agreement has been reached on the level of commitment that can be assumed to exist; some theoretical models disregard the issue altogether by assuming full commitment, while others postulate that agents renegotiate on a regular basis. An increasingly popular framework, the Limited-commitment Intertemporal Collective (or LIC) model $^{2}$, adopts an intermediate view: contracts are assumed to be constrained efficient given limits on individuals's ability to commit (e.g., under most legal regimes they cannot commit not to divorce).

Commitment considerations have important implications regarding the consequences of monetary shocks experienced by one of the spouses. Take for instance a decline in a spouse's wage. Under full commitment, this should have no impact on divorce: spouses should fully insure each other against such shocks, including large ones. In a LIC context, patterns are more complex. Small shocks should indeed have no impact, since they will be smoothed by risk sharing mechanisms within the household. There is however a limit to shocks that can be absorbed by existing arrangements. In particular, the shock may be so large that continuing with the initial agreement would violate individual rationality: one spouse at least would become worse off remaining married than (s)he would be if divorced. In that case, two outcomes are possible: either a renegotiation on intrahousehold allocation succeeds in preserving the marital link, or no such agreement exists and the couple divorces. This distinction between small shocks that should be insured away and large ones which may trigger divorce is central to our empirical strategy.

Lastly, while marital gains depend in part on spouses' ability to commit, the opposite effect is also present. To the extent that marital gains involve investments from both parts,

\footnotetext{
${ }^{2}$ See Chiappori and Mazzocco (forthcoming) for a survey.
} 
they tend to increase the value of a maintained relationship, therefore increasing the level of commitment available. A typical example is children. On the one hand, investing in fertility and children's human capital is a long term decision, for which some minimal level of commitment is needed. Conversely, such investments, once realized, increase the costs of separation, therefore stabilizing the relationship. This intuition dates back to Becker et al. (1977), who explain the stabilizing effect of children via their role as marital-specific capital. By definition, marital-specific capital increases marital gains in the current marriage more than outside utility. This drives down the probability of divorce. As we shall see, these standard predictions are confirmed in our data.

Remarriage A third set of issues is related to remarriage. In evaluating the expected utility after divorce, individuals take into account remarriage prospects: this is the option value of divorce. This has several implications. First, it is hard to model divorce and remarriage, and more generally the most important household decisions, without adopting an equilibrium approach. Whether the issue is investment in education, choice of a geographical location, or agreeing to divorce, the intra-household decision process indeed depends on the spouses' outside options, which play an important role in the intrahousehold allocation of resources and welfare. However, these outside options are themselves linked not only to the probability of finding a new mate in case of divorce, but also to the allocation of welfare that would prevail within the hypothetical new household; and that in turn is endogenous and determined by similar mechanisms. In other words, intrahousehold allocation is intrinsically an equilibrium phenomenon.

Allowing for remarriage also changes the theoretical analysis of the consequences of unexpected income shocks. Consider a positive and permanent shock that boosts expectations about one of the spouses' future income. In principle, such a shock increases both marital gain and the person's expected utility when single. However, most mechanisms that lie behind the notion of marital gains, such as of public consumptions within households, have a dual effect. First, they make the effect of positive income shocks larger within marriage than when single, if only because this spouse now can spend part of the additional income on goods and services that also benefit other family members. If divorce means remaining single forever, positive income shocks therefore should decrease divorce probabilities. But the mechanisms that underlie marital gains also tend to imply positive assortative matching on income - and most data sets, including ours, strongly support such predictions. Remarriage introduces the possibility of "rematching up" to a higher income partner; and re-entering the marriage market in a better economic position may result in a new and "better" match, 
inflating the value of additional income outside the current marriage. If the probability of remarriage is high enough, large positive income shocks will make divorce more likely. Note, finally, that remarriage probabilities typically differ across genders; men remarry more frequently than women. While an explanation for this difference is beyond the scope of this paper, we should expect the impact of economic shocks on divorce probabilities to depend on the gender of the spouse who is hit by the shock.

\section{Data}

The data we use are drawn from the Russia Longitudinal Monitoring Survey (RLMS). This is an annual panel data based on nationally representative surveys designed to monitor the effects of Russian reforms on the health and economic welfare of households and individuals in the Russian Federation. It is jointly conducted by the Carolina Population Center at the University of North Carolina at Chapel Hill (USA) and the Demoscope team of the High School of Economics (Russia).

Our study is based on rounds 6-22 of the survey, from the period 1995-2013. These rounds have all been published. At each round, the RLMS interview was completed with the household members in the original sample dwelling unit. The RLMS is thus a longitudinal study of population dwelling units. The target sample size was set at 4000 households. In 2010 the sample was augmented by 2000 households.

The survey is made up of household and individual questionnaires ${ }^{3}$. The household part of the survey provides information on household structure, living conditions, expenditures, and incomes. The individual part of the survey covers in detail marital status, employment, education and health. Moreover, the individual questionnaire contains a number of questions pertaining to subjective welfare and beliefs regarding political and economic issues.

Our sample consists of married couples living together or breaking up over the course of our panel. We only kept couples whose two partners had non-missing values of the demographic and socioeconomic characteristics thought to influence the divorce hazard and subjective data. This allows us to predict the non-monetary component of the marriage output. Since we are studying the transition from married to divorced status of individuals, we also need information from at least two consecutive periods of time. This gives us a working sample of

\footnotetext{
${ }^{3}$ There are also child and community-level questionnaires. The latter provides information on regionspecific prices and community infrastructure.
} 
5,346 couples. $20 \%$ of these couples are observed only twice over the course of the 1995-2013 period. The frequencies of longer spells decay progressively, from about $19 \%$ for couples observed over a three-year period to $2 \%$ for couples observed over 10 to 15 years.

Table A.1 in the Appendix provides some basic descriptive statistics about the sample. Men are two years older than women; spouses' education attainments are similar, but men earn about $30 \%$ more than women. The table also reports the distribution of the subjective data we will use at different stages of our empirical analysis.

\subsection{Assortative Matching}

The data fit our assumption of positive assortative matching on income: spouses' wages are positively correlated. The last five rounds we use (rounds 18-22 of the RLMS) provide information on the duration of marriage among the observable couples and thus allow us to evaluate the correlation between wages at different levels of duration. Table A.2 in the Appendix reports estimates of a linear regression relating wife's wage to husband's wage, controlling for her age and education and taking into account random effects. Different thresholds for duration $(3,5,9,14,19,24,30,34$ and 42 years) correspond to the deciles of marriage duration in the sample. As can be seen from the table, the correlation decays slowly with the duration of marriage but it is always positive. Its value is slightly lower than in the US for instance, where Browning et al.(2014) report 0.4 correlation between spouses' wages. They attribute the positive sorting to reduced specialization within US couples: an increase in female labor supply over recent decades and technological advance discouraged traditional division of labor exploiting comparative advantages by allocating wives's labor to the household production and husbands' labor to the market activity; in the traditional framework, specialization of spouses' labor maximized the marital output and yielded the highest gain under a negative correlation between their wages (Becker, 1973).

\subsection{Divorce and remarriage}

In the US and Western Europe, the divorce rate doubled from the mid-1960s to the mid-1985, reaching an annual population rate of 3-5\% depending on the country. Since then it has had country-specific fluctuations with no clear trend (Browning et al., 2014). The divorce rate in Russia has followed roughly the same trajectory. As illustrated by Figure 1, since the 1990s and in particular over the period of study, the Russian divorce rate has fluctuated, 
with a strong peak in 2000 and a moderate peak in $2009^{4}$. These fluctuations do not have an obvious cause since the divorce legislation did not change in the 1990s (Population of Russia, 2014). According to the Russian population census of 2010-2011, the annual divorce rate among married couples is $22 \%$. The RLMS data exhibits the same rate (Table 1 ). Over the course of our panel, $21 \%$ of couples broke up.

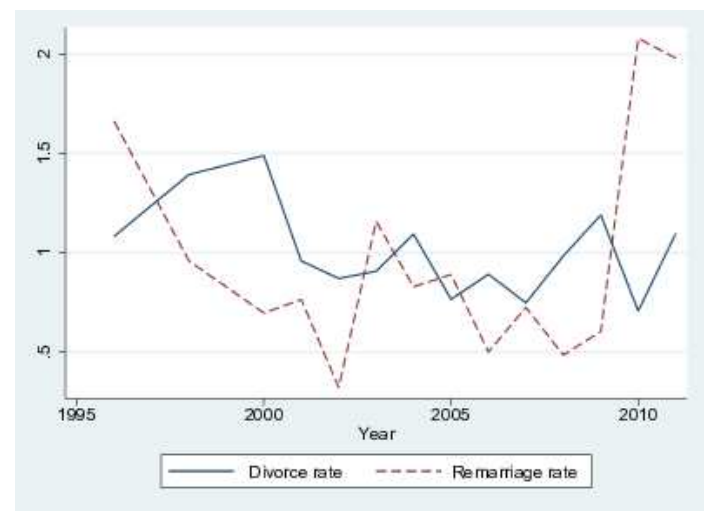

Figure 1: Sample divorce and remarriage rates among married couples, \% Source: RLMS, 1995-2013

\begin{tabular}{|l|c|}
\hline \multicolumn{2}{|c|}{ Russian population, 2010-2011 } \\
\hline Annual divorce rate among married couples \\
\hline \multicolumn{2}{|c|}{ RLMS panel } \\
\hline Annual divorce rate among adults, 2010 & $22 \%$ \\
Annual divorce rate among married couples, 2010 in use & $15 \% 0$ \\
\hline \multicolumn{2}{|c|}{ Sample } \\
\hline Divorce transition occurrences & $974(6.2 \%)$ \\
Number of couples & 5346 \\
Period of observation, mean & 4 \\
Period of observation, standard deviation & 3 \\
Fraction of couples broken up over the course of the panel & $18 \%$ \\
\hline Number of observations & 15843 \\
\hline
\end{tabular}

Table 1: Divorce rates

The dashed line of Figure 1 shows that divorces have often been followed with second marriages since the 2000s. It is common to observe a higher marital turnover accompanying a higher divorce rate; a larger number of divorcees increases remarriage probability, stimulating further divorces and remarriages (Browning et al., 2014). Figure 2 shows the share of

\footnotetext{
${ }^{4}$ Note that the reference rate here if the rate among married couples, which is roughly three times the rate among the adult population.
} 
second marriages in all marriages during 1995-2011. A higher remarriage rate among men as reported by the Russian Federal State Statistics Service data (the left-side graph) is also a common finding; it can be explained by the larger proportion of divorced and widowed women at older ages, the traditional age difference between spouses, and male earnings increasing more than female earnings over the lifecycle. The right-side graph based on the RLMS data displays similar time trends while do not show gender gap. This might be explained by the fact that the RLMS survey do not attempt to follow up with divorced individuals who leave their marital dwelling units.
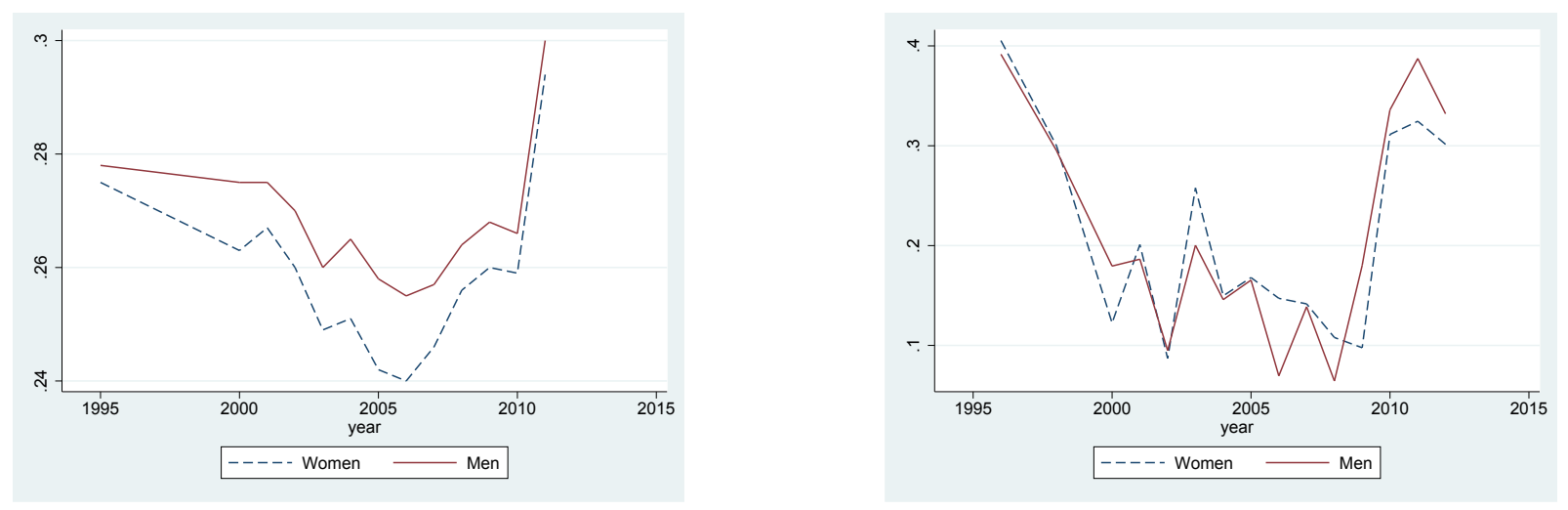

Figure 2: Share of second marriages

Source: Russian Federal Statistics Service (left panel) and RLMS (right panel)

\section{Quality of marriage as a component of life satisfaction}

We use subjective well-being data to evaluate each spouses' perception of the quality of match. Subjective well-being is addressed in the individual questionnaire of the survey, where each individual is asked to rank their satisfaction with life using a 5-level scale where 1 corresponds to the highest level of satisfaction.

The happiness literature shows that marriage is one of several aspects of the satisfaction with life reported by individuals. Among other factors are satisfaction with economic conditions, employment, and health (see for example Van Praag, 2007; Kalugina, Radchenko and Sofer, 2009a, b; Radchenko, 2015). We employ various subjective reports from this section of RLMS to explore variations in individuals' levels of satisfaction and their relationship with various aspects of their life. Additional subjective information is conveyed through individuals' selfranking among the poor and rich, on a scale ranging from 1 , the poorest, to 9 , the richest. The survey also reports individuals' ranking of their health status, ranging from 1 (very 
good) to 5 (very bad). Moreover, rounds 9-22 (1998-2013) provide self-reported satisfaction with economic conditions, evaluated over the same 5-level scale as the scale of satisfaction with life. Rounds 11-22 (2002-2013) also report information on job satisfaction as well as satisfaction with job conditions, payment and career growth opportunities ${ }^{5}$. In what follows, the health status and all the satisfaction variables are recoded to follow conventional scale where the lowest (highest) value corresponds to the lowest (highest) level of satisfaction or health evaluation.

Finally, round 11 provides information on various aspects of the relationship within couples, from bonds and caring to displeasure. Positive reports on the attitude of one's partner are obtained from answers to questions including agreement and support, caring, advising, listening, making confident, understanding the way of thinking, and helping. On the negative side, there are answers to the questions focusing on his or her aggressive behavior, complicating one's life, showing displeasure, lack of desire for a sexual relationship, criticizing, and offending. The answers are given at a scale describing frequencies of different behavioral occurrences: 1 (never); 2 (sometimes); 3 (always).

Answers related to a positive attitude of the partner are highly positively correlated (about 0.5 correlation), as are answers referring to the negative attitude. We will focus on the positive and the negative questions whose answers have the highest rate of responses: supportive behavior, and behavior showing displeasure. The first two columns of Table 2 show the correlations between satisfaction with life and satisfaction with economic conditions (column 1) or economic ranking (column 2) as well as with partnership quality and health ranking. The correlations result from linear regressions based on round 11 (2002), which provided information on partnership quality. Regressors are strongly correlated with satisfaction with life. This shows that economic satisfaction, health, and partnership quality are indeed the traits of the overall satisfaction with life. The last column of Table 2 shows that satisfaction with economic conditions captures variations in one's wage and satisfaction with the job payment. The estimates correspond to a fixed-effects linear regression run over rounds 11-22 (2002-2013), which provided information on economic satisfaction.

Overall, the data support the main findings reported in the literature on the components of satisfaction. When running the empirical analysis, we will purge the reported match qualities from variations due to economic conditions and health; section 5.1.2 provides more details.

\footnotetext{
${ }^{5}$ Individual evaluations are again given on a scale ranging from 1 , the highest level of satisfaction, to 5 .
} 


\begin{tabular}{|c|c|c|c|}
\hline & Satisfaction $^{\text {a) }}$ & Satisfaction $^{\text {a) }}$ & $\begin{array}{c}\text { Satisfaction with } \\
\text { economic conditions }\end{array}$ \\
\hline Satisfaction with economic conditions ${ }^{a}$ & $\begin{array}{l}.492^{* * *} \\
(.011)\end{array}$ & & \\
\hline Economic rank $\mathrm{k}^{\mathrm{b})}$ & & $\begin{array}{l}.248^{* * *} \\
(.009)\end{array}$ & \\
\hline Spouse's supportc) & $\begin{array}{l}.209 \\
(.022)\end{array}$ & $\begin{array}{l}.253^{* * *} \\
(.024)\end{array}$ & \\
\hline Spouse's displeasure ${ }^{\mathrm{c})}$ & $\begin{array}{c}-.099^{* * *} \\
(.025)\end{array}$ & $\begin{array}{c}-.128^{* * *} \\
(.027)\end{array}$ & \\
\hline Health evaluation ${ }^{\mathrm{d})}$ & $\begin{array}{l}.255^{* * *} \\
(.017)\end{array}$ & $\begin{array}{l}.242^{* * *} \\
(.019)\end{array}$ & \\
\hline Wage $(\ln )$ & & & $\begin{array}{l}.121^{* * *} \\
(.012)\end{array}$ \\
\hline Spouse's wage $(\ln )$ & & & $\begin{array}{l}.028^{* *} \\
(.012)\end{array}$ \\
\hline Satisfaction with job ${ }^{\text {a) }}$ & & & $\begin{array}{l}.062^{* * *} \\
(.009)\end{array}$ \\
\hline Satisfaction with job payment ${ }^{\mathrm{a})}$ & & & $\begin{array}{l}.218^{* * *} \\
(.007)\end{array}$ \\
\hline Spouse's satisfaction with job payment ${ }^{\mathrm{a})}$ & & & $\begin{array}{l}.079^{* * *} \\
(.006)\end{array}$ \\
\hline Satisfaction with work conditions ${ }^{\text {a) }}$ & & & $\begin{aligned}-.014^{*} \\
(.009)\end{aligned}$ \\
\hline Satisfaction with professional opportunities ${ }^{\mathrm{a})}$ & & & $\begin{array}{l}.031^{* * *} \\
(.007)\end{array}$ \\
\hline Constant & $\begin{array}{c}0.599^{* * *} \\
(0.093)\end{array}$ & $\begin{array}{c}0.708^{* * *} \\
(0.103)\end{array}$ & $\begin{array}{c}2.98^{* * *} \\
(.073)\end{array}$ \\
\hline$N$ & 6095 & 6075 & 29706 \\
\hline adj. $R^{2}$ & 0.360 & 0.171 & 0.256 \\
\hline
\end{tabular}

a) 1: not at all satisfied;...5: strongly satisfied

b) 1: poor;... 9: rich

c) 1: never; 2 : sometimes; 3 : always

d) 1: very bad; ...5: very good

Standard errors in parentheses. ${ }^{* * *} p<0.01,{ }^{* *} p<0.05,{ }^{*} p<0.1$

Table 2: Correlation between satisfaction levels and various aspects

\section{$5 \quad$ Empirical model}

The empirical analysis consists of two stages. First, we construct monetary and nonmonetary shocks as residuals of wage and satisfaction regressions. Second, we estimate 
the divorce hazard model using the predictions from the first stage.

\subsection{Monetary and non-monetary shocks}

\subsubsection{Wage equations}

We define idiosyncratic monetary shocks as the residuals of the following fixed effects linear regressions:

$$
W_{j t i}=\gamma_{j} X_{j t i}+\pi_{j t}+u_{j i}+w_{j t i}
$$

where $j=m, f$ is the gender of an individual observed in couple $i$ at time $t$, and $W_{j t i}$ is the logarithm of the hourly wage.

We follow Lacroix and Radchenko (2011) in specifying different wage equations for men and women. $X_{j t i}$ is a vector of individual wage determinants (education, age, age squared). The fixed effects $\pi_{j t}$ stand for a macroeconomic shock at time period $t$, and the fixed effects $u_{j i}$ capture unobservable time invariant wage determinants. Finally, $w_{j t i}$ represents idiosyncratic wage shocks at time period $t$.

The unobserved heterogeneity factors $u_{m i}$ and $u_{f i}$ relate to time-invariant labor market situations of man and woman in household $i$, and to unobserved personal characteristics that impact individual wages. $u_{m i}$ and $u_{f i}$ may be correlated through positive assortative matching of spouses. $u_{m i}$ and $u_{f i}$ may also capture "permanent" shocks on the value of human capital ${ }^{6}$.

The expected wage rate implied by (1) is defined as

$$
\hat{W}_{j t i}=\hat{\gamma}_{j} X_{j t i}+\hat{u}_{j i}
$$

Note that we choose not to consider aggregate wage shocks $\left(\pi_{j t}\right)$ as monetary shocks impacting divorce hazard. The reason is that these shocks do not vary across individuals of a given gender. As such, they should mostly shift the distribution of wages within couples, without impacting relative earning abilities within the respective gender groups. Given positive

\footnotetext{
${ }^{6}$ We attempted to estimate more complex wage equations with highly persistent shock (modeled by a random walk) or serially correlated temporary shocks. Unfortunately, the panel dimension does not seem to be strong enough to identify such structures.
} 
assortative matching based on incomes, the aggregate shocks would not impact remarriage prospects and the divorce hazard ${ }^{7}$.

\subsubsection{Quality of matching}

In our model of divorce, we took the evolution of match qualities $\boldsymbol{\theta}=\left(\theta_{f}(m), \theta_{m}(f)\right)$ to be exogenous. It reflects the evolution of partners' relationship and the intensity of their connection. The model does not explicitly allow $\boldsymbol{\theta}$ to change in anticipation of the post-divorce utility. However, the restriction does not induce an endogeneity bias in our estimates of $\boldsymbol{\theta}$. Suppose for instance that the wife fears a unilateral divorce. In such a case, an exogenous drop in her husband's perception of the quality of the marriage might cause her $\theta_{f}$ to decrease. But this is simply a correlation between the two components of $\boldsymbol{\theta}$; our theoretical model allows for it, and we explicitly address it in the empirical model by allowing $\theta_{f}(m)$ and $\theta_{m}(f)$ to be correlated.

The residual values representing the evolution of $\boldsymbol{\theta}$ are obtained by estimating the following system:

$$
\begin{aligned}
\text { satlif }_{f t i} & =\alpha_{11} \text { satlif }_{m t i}+\alpha_{12} \text { satecon }_{f t i}+\alpha_{13} \text { healt }_{f t i}+ \\
& +\alpha_{14} W_{f t i}+\alpha_{15} W_{m t i}+\alpha_{16} \text { age }_{f t i}+\tau_{f t}+\theta_{f t i} \\
\text { satlif }_{m t i} & =\alpha_{21} \text { satlif }_{f t i}+\alpha_{22} \text { satecon }_{m t i}+\alpha_{23} \text { health }_{m t i}+ \\
& +\alpha_{24} W_{m t i}+\alpha_{25} W_{m t i}+\alpha_{26} \text { age }_{m t i}+\tau_{m t}+\theta_{m t i}
\end{aligned}
$$

Here $f$ and $m$ stand for women and men respectively; $i$ and $t$ are, as previously, couple and time subscripts. satlife and satecon stand for variables representing satisfaction with life and self-rating among rich and poor respectively; health represents subjective health evaluation; $\tau_{f t}$ and $\tau_{m t}$ are time fixed effects.

This stage of the empirical analysis omits individual fixed effects that might be related to such individual characteristics as pessimism or optimism. However, not controlling for the

\footnotetext{
${ }^{7}$ They can affect the divorce hazard via the probability of singlehood. However, the wage rate increased over the whole period, and the time dummies are likely to also reflect the effects of inflation despite the CPI used to adjust the nominal wages.
} 
fixed effects is not as restrictive as it might seem at first glance. Indeed, the regression includes satisfaction with economic conditions and health as explanatory variables. These variables are subjective indicators as well; the correlation between satlif and these variables is partly due to the common fixed effects related to individual perceptions. Controlling for these variables filters the variations that are due to satisfaction with economic conditions and health, but also provides a control for fixed effects related to individual subjectivity.

\subsection{Divorce equation}

Our empirical model of divorce defines the probability of transition from married to divorced status of the partners ${ }^{8}$ :

$$
P\left(D_{t+1, i}=1 \mid D_{t, i}=0\right)=\Phi\left(S_{t i}+\beta_{m} \hat{\theta}_{m t i}+\beta_{f} \hat{\theta}_{f t i}+\beta_{X} X_{t i}+\lambda_{t}+d_{i}\right)
$$

where $\Phi$ stands for the standard normal cdf and $D_{t, i}$ is a dummy variable that equals one if the individual reports being divorced at date $t$ and zero otherwise. Since the divorce procedure takes up to several months with the minimum pace of one month, the decision to divorce by year $(t+1)$ is assumed to be taken in year $t$ based on the corresponding information set $I_{t}$.

In line with the conceptual setting, the divorce hazard depends on both monetary and non-monetary shocks. These two main components of the information set are $S_{t i}$, which represents the economic surplus for couple $i$ at time $t$, and $\left(\hat{\theta}_{m t i}, \hat{\theta}_{f t i}\right)$ which represent the non-monetary shocks to the match quality of the couple and are calculated as residuals of system (3). In addition to the expected wage rates of the spouses at time $t$ defined by (2), the economic component $S_{t i}$ includes covariates $w^{q_{10}}{ }_{j t i}$ and $w^{q_{90}}{ }_{j t i}$ standing for the strong wage shocks from the lower and upper tails of the wage distributions ${ }^{9}$; it also comprises covariates $u n e m_{t i}^{f}$, unem $m_{t i}^{m}$ and $u n e m_{t i}^{f m}$ corresponding to the indicators of unemployment episodes experienced by time $t$ by one of the spouses, woman or man, and both spouses respectively. The $S_{t i}$ component is allowed to be non-monotonic in the wage shocks defined as residuals of $(1)$ :

\footnotetext{
${ }^{8}$ Unfortunately, most rounds of the survey do not provide data on marriage duration. This makes it impossible to use a duration model of the divorce hazard. However, the duration of marriage is highly correlated with age, which we include on $X_{t i}$ (estimation based on the few rounds that have information on marriage duration show that the correlation with age is 0.9 ).

${ }^{9}$ The specification using the tail terms is motivated by our analysis of the distributions of the wage components obtained from (1), which we discuss in section 6 .
} 


$$
\begin{aligned}
S_{t i}= & \beta_{11} \hat{W}_{f t i}+\beta_{12} \hat{W}_{m t i}+\beta_{21} w_{f t i}+\beta_{22} w_{m t i} \\
& +\beta_{23} w^{q_{10}}{ }_{f t i}+\beta_{24} w^{q_{90}}{ }_{f t i}+\beta_{25} w^{q_{10}}{ }_{m t i}+\beta_{26} w^{q_{90}}{ }_{m t i}+ \\
& +\beta_{27} w^{q_{90}}{ }_{m t i} \cdot w^{q_{90}}{ }_{f t i}+\beta_{28} w^{q_{10}}{ }_{m t i} \cdot w^{q_{10}}{ }_{f t i}+ \\
& +\beta_{31} \text { unem }_{t i}^{f}+\beta_{32} \text { unem }_{t i}^{m}+\beta_{33} \text { unem }_{t i}^{f m}
\end{aligned}
$$

where

$$
\begin{aligned}
& w^{q_{10}}{ }_{j t i}=\min \left(w_{j t i}-q_{w_{j}, 10}, 0\right) \\
& w^{q_{90}}{ }_{j t i}=\max \left(w_{j t i}-q_{w_{j}, 90}, 0\right)
\end{aligned}
$$

with $q_{w_{j}, 10}$ and $q_{w_{j}, 90}$ denoting the 10 th and 90 th percentiles of the $w_{j}$ distribution ${ }^{10}$. This allows for some nonlinearity in the dependence of the divorce probability on wage shocks.

Finally, $X_{t i}$ and $d_{i}$ are couple-level observable and unobservable heterogeneity. They contain the couple's demographic and human capital characteristics, as well as unobserved characteristics impacting the marriage stability of couple $i$. We also allow for regional differences and for time fixed effects $\lambda_{t}$.

\section{Results}

\subsection{Wage equations}

Table 3 shows fixed effects estimates of the wage equations (1) for men and women. The equations are estimated using a sample of working individuals which is considerably larger than our main sample based on a selection of the rounds providing the necessary information. Using this extended sample allows us to obtain precise and efficient estimates of wage determinants while including a rich set of fixed effects. As expected, wages are positively correlated with age, years of education, and experience ${ }^{11}$. Figure 3, which shows univariate

\footnotetext{
${ }^{10}$ The 10th and 90th percentiles of the log-wage shock distributions are roughly -0.5 and 0.5 for both gender groups, so that our "strong shocks" are larger than approximately $50 \%$ in absolute value.

${ }^{11}$ The return to human capital is stable over the observational window. The parsimonious model reported excludes interactions between human capital variables and time.
} 
distributions of male and female wage shocks among divorcees and among women and men remaining married, suggests that the divorce probability is sensitive to strong positive or negative male shocks but is insensitive in regards to female shocks. Figure 4 illustrates the joint distribution of spouses' shocks.

Figure 5 depicts the distributions of the expected wage rates $\hat{w}_{m t i}$ and $\hat{w}_{f t i}$ among divorcees and among married men and women. Perhaps surprisingly, the distribution of female expected wage rates shows that divorced women tend to earn higher wages than married women. Figure 6 clarifies the issue by showing that the difference between wife's and husband's expected wage rates for couples that divorce is also to the right of that for couples that stay married. Thus, the wage estimates suggest that couples in which women earn higher wages than their spouses dissolve more frequently, as compared to the couples in which women earn lower wages.

\begin{tabular}{|c|c|c|}
\hline & Wife's wage $(\ln )$ & Husband's wage (ln) \\
\hline Age & $\begin{array}{l}.029^{* * *} \\
(.011)\end{array}$ & $\begin{array}{c}0.049^{* * *} \\
(.011)\end{array}$ \\
\hline Age squared & $\begin{array}{c}-.0005^{* * *} \\
(.000)\end{array}$ & $\begin{array}{c}-.0006^{* * *} \\
(.000)\end{array}$ \\
\hline Years of education & $\begin{array}{l}.009^{* * *} \\
(.003)\end{array}$ & $\begin{array}{l}.008^{* * *} \\
(.003)\end{array}$ \\
\hline Constant & $\begin{array}{c}3.30^{* * *} \\
(.317)\end{array}$ & $\begin{array}{c}3.15^{* * *} \\
(.289)\end{array}$ \\
\hline $\begin{array}{l}\text { Fraction of residuals variance } \\
\text { related to the time-invariant component }\end{array}$ & 0.66 & 0.61 \\
\hline$N$ & 50279 & 44516 \\
\hline
\end{tabular}

Table 3: Spouses' wage equations (fixed effects estimates) 

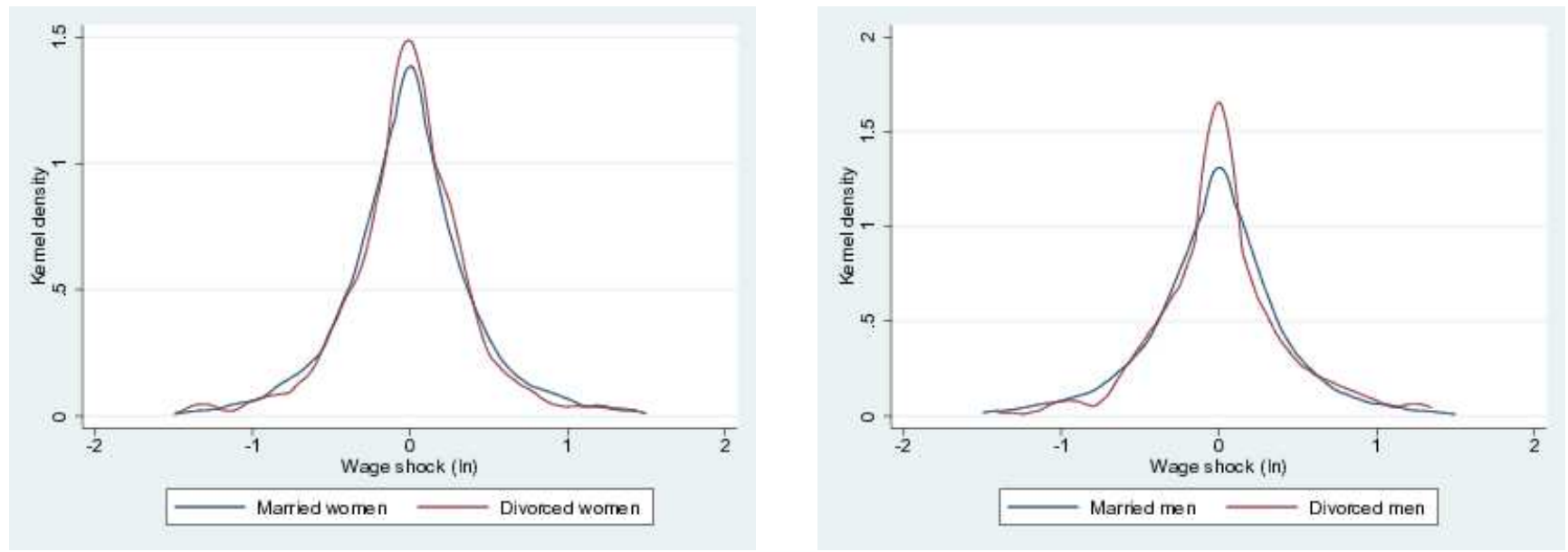

Figure 3: Distribution of the wage shocks.
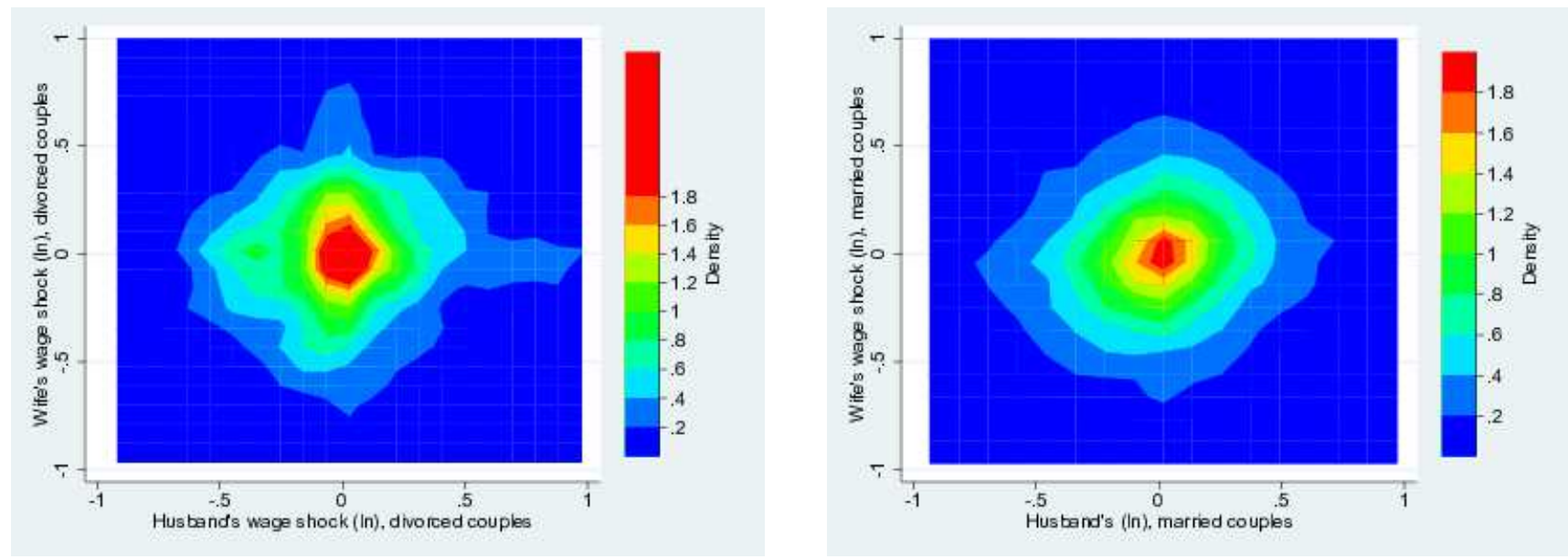

Figure 4: Bivariate distribution of the wage shocks. 

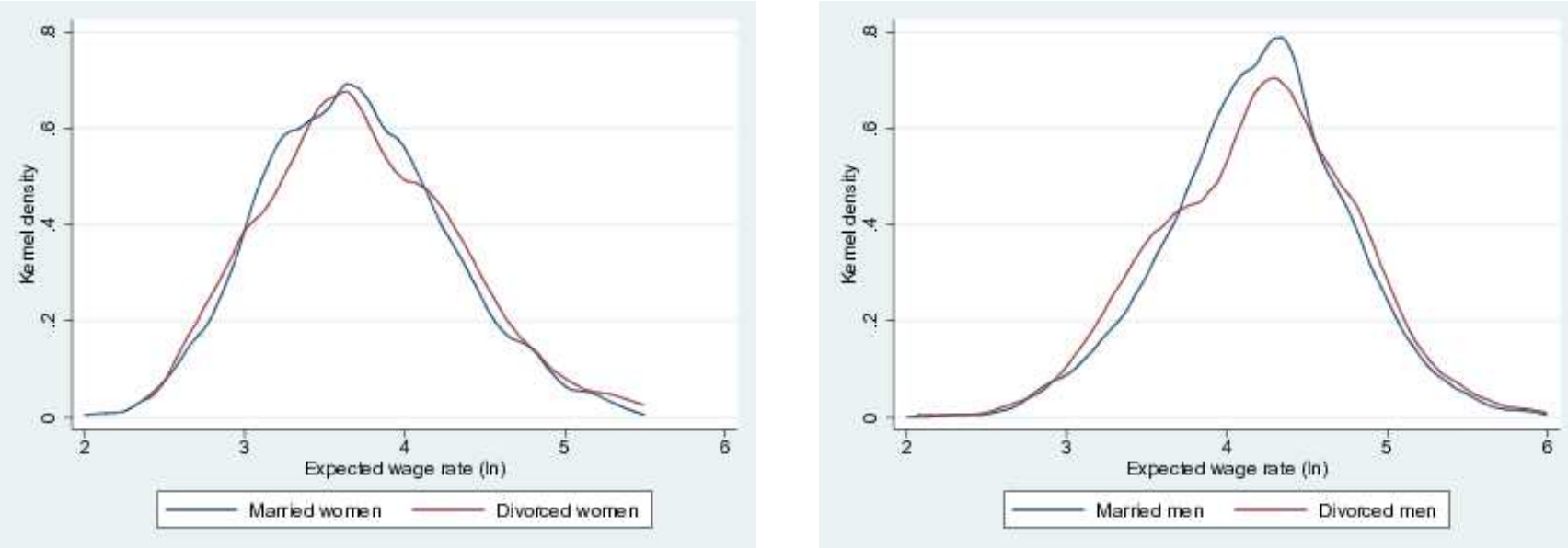

Figure 5: Distribution of the expected wage rates
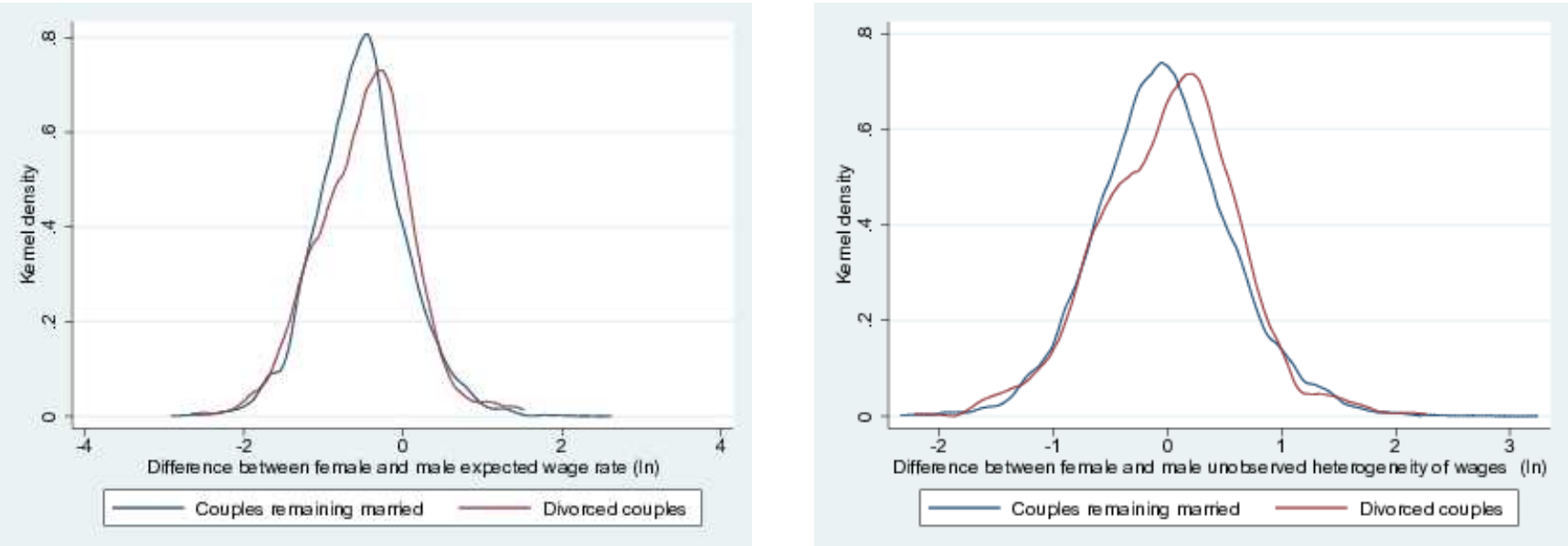

Figure 6: Distribution of the differences between female and male expected wage rates (left panel) and unobserved heterogeneity (right panel)

\subsection{Perceived match qualities}

We estimate system (3) by three-stage least-squares method using an extended sample of couples with the necessary information. Table 4 reports our estimates. Wives' and husbands' levels of satisfaction are positively correlated. Higher wages of both spouses yield higher levels of each partner's satisfaction. Spouses' economic and health ranking are also positively correlated with their satisfaction. Time effects (not reported) are similar among the spouses, with stronger amplitude for women than for men. A large decrease in satisfaction is associated with the period of 1996-2000. This is in line with results of Kalugina et al. 
(2009b) that register a significant negative impact of the economic crisis of 1998 on spouses' subjective well-being. A similar effect occurs in the 2008 recession.

Figure 7 shows that the distributions of $\hat{\theta}_{f t}$ and $\hat{\theta}_{m t}$ for married individuals dominate those of divorcees. This provides our first empirical evidence of a negative relationship between divorce hazard and the quality of matches.

\begin{tabular}{|c|c|c|}
\hline & Wife's satisfaction ${ }^{\mathrm{a})}$ & Husband's satisfaction ${ }^{a)}$ \\
\hline \multirow[t]{2}{*}{ Spouse's satisfaction $^{a)}$} & $.278^{* * *}$ & $.287^{* * *}$ \\
\hline & $(.024)$ & $(0.026)$ \\
\hline \multirow[t]{2}{*}{ Own wage $(\ln )$} & $.115^{* * *}$ & $.068^{* * *}$ \\
\hline & $(.000)$ & $(.009)$ \\
\hline \multirow[t]{2}{*}{ Spouse's wage (ln) } & $.046^{* * *}$ & $.047^{* * *}$ \\
\hline & $(.009)$ & $(.010)$ \\
\hline \multirow[t]{2}{*}{ Economic $\operatorname{rank}^{\mathrm{b})}$} & $.155^{* * *}$ & $.166^{* * *}$ \\
\hline & $(.006)$ & $(.006)$ \\
\hline \multirow[t]{2}{*}{ Health evaluation ${ }^{\mathrm{c})}$} & $.214^{* * *}$ & $.231^{* * *}$ \\
\hline & $(.012)$ & $(.012)$ \\
\hline \multirow[t]{2}{*}{ Age } & $-.003^{* * *}$ & 0.001 \\
\hline & $(.001)$ & $(.001)$ \\
\hline Time fixed effects & Yes & Yes \\
\hline \multirow[t]{2}{*}{ Constant } & $1.247^{* * *}$ & $1.295^{* * *}$ \\
\hline & $(.077)$ & $(.075)$ \\
\hline$N$ & 19664 & 19664 \\
\hline$R^{2}$ & 0.36 & 0.34 \\
\hline
\end{tabular}

a) 1: not at all satisfied;...5: strongly satisfied

b) $1:$ poor; ... 9: rich

c) 1 : very bad; $\ldots .5$ : very good

Standard errors in parentheses. ${ }^{* * *} p<0.01,{ }^{* *} p<0.05,{ }^{*} p<0.1$

Table 4: Spouses' satisfaction (3SLS estimates) 

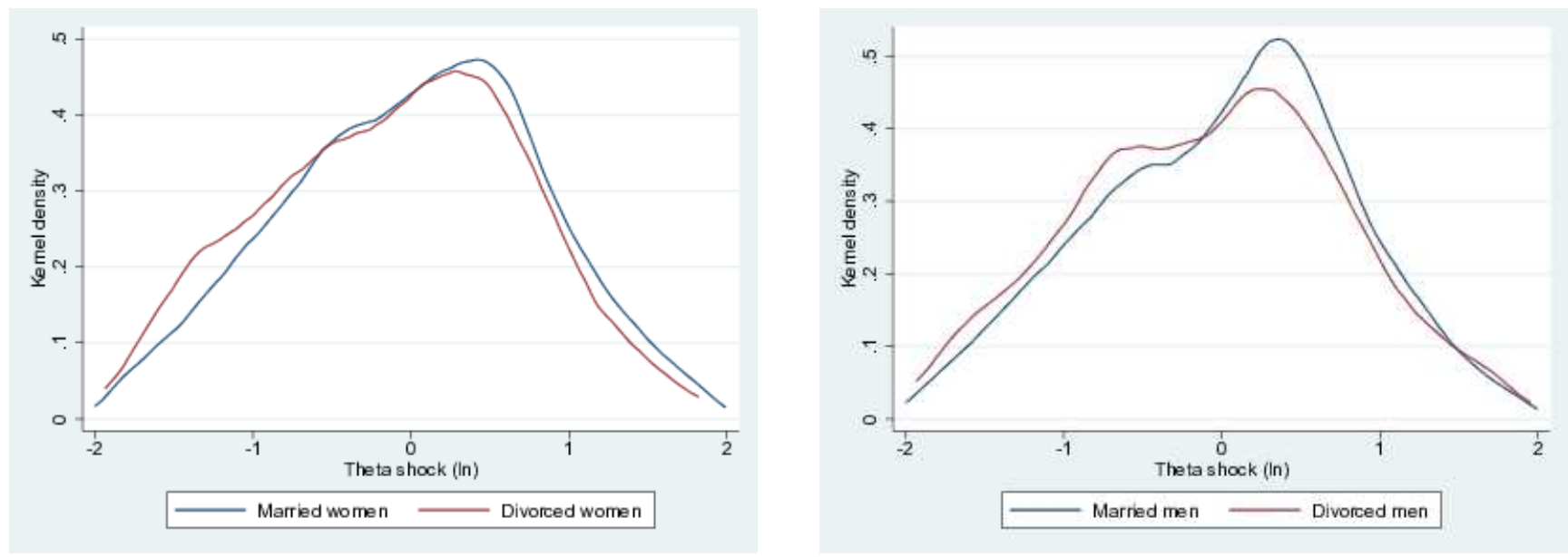

Figure 7: Distribution of the $\boldsymbol{\theta}$ shocks

\subsection{Divorce}

We estimate divorce model (4) using a random effects probit regression. Table 5 reports the estimates. To interpret them, recall that the higher $\theta$ is, the higher the non-monetary benefit of marriage. In line with our conceptual framework, the model estimates show that both monetary and non-monetary factors influence the likelihood of divorce. More interestingly, we could not find any significant impact of the interaction terms constructed as products of $\left(\theta_{f}, \theta_{m}\right)$ and wage-related variables: a likelihood-ratio test does not reject the null hypothesis of joint irrelevance of the interacted terms (the corresponding test statistic is 13.3 and the $5 \%$-critical value of a $\chi^{2}(8)$ is 15.5$)^{12}$. This result validates the assumption that the monetary and non-monetary ingredients enter the marital output additively.

Again in line with the theoretical background, we found that the probability of divorce was insensitive to the "small" shocks: the estimates corresponding to the central parts of the wage distribution $q_{w_{j t i}, 10}<w_{j t i}<q_{w_{j t i}, 90}$ are small and statistically insignificant (see A.3 in Appendix). We excluded them from the regression whose results are in Table 5 .

We also observe a significantly negative relationship between the likelihood of divorce and the number of children and educational achievements. These are classical findings; they were reported in the literature using US data (Becker et al., 1977; van der Klaauw, 1996; Weiss and Willis, 1997). Becker et al. explain the stabilizing effect of children via their interpretation as marital-specific capital. By definition, marital-specific capital increases marital gains in the current marriage more than outside utility. This drives down the probability of divorce.

\footnotetext{
${ }^{12}$ The corresponding specification is not reported but is available on request.
} 


\begin{tabular}{|c|c|c|c|}
\hline \multicolumn{2}{|l|}{ Monetary determinants } & \multicolumn{2}{|l|}{ Non monetary determinants } \\
\hline Husband's strong positive wage shock ${ }^{\mathrm{a}}$ ) & $\begin{array}{l}.300^{*} \\
(.184)\end{array}$ & Wife's $\theta^{\text {c) }}$ & $\begin{array}{c}-.214^{* * *} \\
(.037)\end{array}$ \\
\hline Husband's strong negative wage shock ${ }^{\mathrm{b}}$ ) & $\begin{array}{l}.473^{* *} \\
(.212)\end{array}$ & Husband's $\theta$ & $\begin{array}{l}-.063^{*} \\
(.036)\end{array}$ \\
\hline Wife's strong positive wage shock ${ }^{\mathrm{a}}$ ) & $\begin{array}{l}-.213 \\
(.214)\end{array}$ & Husband's years of education & $\begin{array}{c}-.037^{* *} \\
(.018)\end{array}$ \\
\hline Wife's strong negative wage shock ${ }^{\mathrm{b}}$ ) & $\begin{array}{l}.098 \\
(.245)\end{array}$ & Wife's minus husband's education & $\begin{array}{c}.016 \\
(.012)\end{array}$ \\
\hline $\begin{array}{l}\text { Wife's strong positive wage shock } \\
\times \text { husband's strong positive wage shock }\end{array}$ & $\begin{array}{l}-.864 \\
(.896)\end{array}$ & Husband's age & -.001 \\
\hline Wife's strong negative wage shock & $1.657^{* *}$ & & $(.004)$ \\
\hline$\times$ husband's strong negative wage shock & $(.825)$ & Wife's minus husband's age & -.013 \\
\hline Wife's unemployment episode & $\begin{array}{l}.281^{* *} \\
(.141)\end{array}$ & & $(.009)$ \\
\hline Husband's unemployment episode & $\begin{array}{c}.063 \\
(.116)\end{array}$ & Number of children & $\begin{array}{l}-.068^{*} \\
(.041)\end{array}$ \\
\hline Joint unemployment episodes & $\begin{array}{c}.757^{* * *} \\
(.187)\end{array}$ & & \\
\hline Expected wife's wage & $\begin{array}{c}.315^{* * *} \\
(.085)\end{array}$ & Regional dummies & Yes \\
\hline Expected husband's wage & $\begin{array}{l}-.095 \\
(.085)\end{array}$ & Year dummies & Yes \\
\hline Within group correlation & $\begin{array}{c}.774^{* * *} \\
(.016)\end{array}$ & Constant & $\begin{array}{c}-3.44^{* * *} \\
(.552)\end{array}$ \\
\hline$N$ & 15843 & & \\
\hline
\end{tabular}

a) $10 \%$ right tail

b) $10 \%$ left tail

c) $\theta$ corresponds to the theoretical $\theta$ : the higher one's $\theta$, the higher one's benefit to marriage Standard errors in parentheses. ${ }^{* * *} p<0.01,{ }^{* *} p<0.05,{ }^{*} p<0.1$

Table 5: Transitions to divorce status (random effects probit estimates)

Reported match quality has a negative impact on marital dissolution: the higher the satisfaction of the spouses, the lower the divorce probability. The effect is much stronger for women: the estimate associated with the female perception of the match quality is about three times larger than the estimate associated with the male perception.

In terms of monetary impacts, the results are specific relative to different economic components included as explanatory variables. The graphs of the wage shocks distributions (Figures 3 and 4) imply that marital stability is especially sensitive to shocks corresponding to the upper and lower $10 \%$ tails of the distribution. In particular, the distribution of shocks 
among divorced men has fatter tails than the distribution of the shocks among men who stay married. This is intuitive, given that our wage shocks are residuals that are one-period lagged relative to the divorce status transition. The shocks represent therefore transitory and/or recent changes; only strong shocks of this kinds are likely to destabilize couples in the short run. The model estimates are in line with the graphical analysis and imply that the divorce likelihood is insensitive to the "small" shocks ${ }^{13}$ : the estimates corresponding to the central parts of the wage distribution are weak and statistically insignificant (see A.3 in Appendix). This is also in line with the theoretical background implying that even under limited commitment the small shocks are smoothed out by intrahousehold risk sharing. The asymmetry between genders - with male shocks being apparently more important is compatible with the higher remarriage rate among men reported by the Russian Federal State Statistics Service data (section 3.2). Such an explanation is also consistent with the theoretical background discussed earlier.

Further, the estimates of the divorce model follow the descriptive graphs and the theoretical background by reporting a positive correlation between strong male wage shocks and divorce. In line with the the theoretical prediction discussed in Section 2, positive shocks raise the attractiveness of remarriage, since assortative matching implies that a new spouse would typically be 'better' than the current one; if remarriage probability is large enough, this may trigger divorce.

Divorce is especially likely when the spouses are hit by shocks of opposite sign. From an insurance viewpoint, these are easier to cover: insofar as the shocks are of similar magnitudes, so that the impact on aggregate income is feeble, the mutuality principle predicts that internal insurance should compensate them out. However, commitment problems are especially severe in this case, particularly when remarriage is easy. Indeed, Figure 8 illustrates how shocks that hit the two partners in opposite ways create a mismatch and increase the probability of divorce. When shocks increase the mismatch between spouses to the detriment of the wife (with a strong positive male shock and a negative female shock), the divorce probability doubles, up to $3 \%^{14}$. These effects of opposite-sign strong shocks are statistically significant, except for very strong shocks which are rarely observed in the data.

As predicted by theory, the disruptive effect of a positive male shock could be counterbalanced by positive changes in the non-economic quality of match $\boldsymbol{\theta}$. Our results indeed show that higher spouses' satisfaction reduces the divorce probability. This effect is genderspecific, however: the estimate associated with the female perception of the match quality is

\footnotetext{
${ }^{13}$ Excluded from the parsimonious estimation reported in Table 5

${ }^{14}$ The annual divorce rate is $2.2 \%$ according to both census and RLMS data for 2010 .
} 
about three times higher than the estimate associated with the male perception of the match quality. Figure 9 shows the predicted divorce probability at different levels of the male satisfaction scale and wage shock. Depending on the magnitude of the shock, the probability goes from $1 \%$ to $4 \%$ at the highest level of $\theta_{m}$ and from $2 \%$ to $6 \%$ at its lowest level.

The positive effect of a male wage shock on the probability of divorce obviously implies that a negative male wage shock reduces the likelihood of divorce. This is an unexpected result. As discussed in section 2, negative shocks to the husband's wage reduce the marital economic gain and should increase the probability that the wife will want a divorce in order to find a better match. The theory implies that a larger deviation between actual and expected wages should make divorce more likely, independently of the direction of the shock. In contrast, our estimates suggest that couples reallocate utility in the short run in order to stay married. This could be due to a low remarriage probability for the woman in the short run, and to longer-term considerations underlying her perspectives as single. Once again, such an explanation is consistent with the higher remarriage rate among men reported by the Russian Federal State Statistics Service data (section 3.2).

When both spouses experience strong unexpected negative shocks, it becomes impossible to reallocate utility so as to keep the marriage stable. The positive estimate of the effect of the product of the strong negative shocks of the spouses $(10 \%$ lower tails of female and male wage shocks) confirms this; but the estimate is only weakly significant ( $10 \%$ significance level). The corresponding probability predictions are statistically significant for "midsized" negative shocks, beyond which observations are too scarce. The estimates associated with unemployment episodes provide more evidence on marital dissolution following unexpected negative shocks experienced by both spouses. Such episodes increase the divorce probability. The marginal effect of the wife's unemployment is weaker than the husband's. The effect is particularly strong if both spouses have been unemployed for some time within the period of observation. These disruptive effects of negative job shocks agree with empirical findings reported in the literature using US and UK data (Battu et al., 2013; Böheim and Ermisch, 2001; Charles and Stephens, 2004; Hess, 2004).

We saw that the marital payoff was sensitive to wage shocks that benefit the husband. Results on the effect of expected wages reveal another gender asymmetry, which goes in the opposite direction. The divorce probability ranges from 0 to $2 \%$ when female expected wages are low, but it increases to up to $8 \%$ at their high levels (Figure 10). Moreover, the corresponding marginal effect also increases with the wife's expected wage. This confirms a common finding of the literature using US data: Becker et al. (1977), van der Klaauw (1996) and Weiss and Willis (1997) also found disruptive effects of higher female earnings. 
One can go further and assert that couples in which the wife's expected wage is larger than the husband's are more likely to divorce. The descriptive graphs shown on Figure 5 already suggest it, and the estimates of the divorce model confirm and specify this effect: Figure 10 shows that the divorce likelihood is high in the area above the main diagonal, and increases with the difference in wages. This finding mirrors to some extent the relationship between the male wage shock and divorce probability. The disruptive effect of a higher female wage may be compensated by a high non-economic quality of match $\boldsymbol{\theta}$. Figure 11 quantifies the effects at different levels of woman's wage and $\theta_{f}$. Depending on the wage level, the probability is no stronger than $2 \%$ at the highest level of $\theta_{f}$ and runs up to $12 \%$ at its lowest level. For high female wages, the variation in $\theta_{f}$ moves the divorce probability by up to 10 points. The marginal effect is stronger at lower levels of the wife's perceived match quality and when the husband has an unfavorable wage shock.

Such patterns might be explained by traditional gender norms within the couples where the man is the main breadwinner - see Becker et al. (1977) and Weiss and Willis $(1997)^{15}$. Note, however, that these US findings are based on 1970s data. The context has changed since then: the turnover on the marriage market is considerably higher, and female labor-force participation is much stronger in Western countries (Browning et al., 2014) and high in Russia (see section 3.2 and Population of Russia, 2014). Early studies reported negative assortative matching on wages (conditional on educations) and attributed it to a high degree of specialization within the couples. More recent estimates find positive assortative matching on spouses' wages, both on US data (Browning et al., 2014) and in the RLMS survey (see section 3.2). In this new context, the disruptive effect of a higher wife-husband wage ratio may simply imply that such women chose their first husbands suboptimally and then reoptimize. Gender asymmetry in the initial matching would follow from a higher search cost for women: with preferences for children, waiting for a better match is more costly for women than for men since their reproductive time horizon is shorter (Low, 2014). Premarital childbearing can also increase women's search cost (Becker et al., 1977), making them more likely to accept a mismatch. There may also be additional explanations specific to Russia. There is evidence that the Russian society still values a patriarchal model of the family, with earlier marriages for women as well as earlier childbearing (Blum et al., 2009). This would act to increase the women's waiting cost further.

Finally, figures 11 and 9 show that $\theta_{f}$ and $\theta_{m}$ are not perfect substitutes in marital output. The slope of the probability isoquant corresponding to the women's graph is roughly twice as high as the slope corresponding to the men's graph (0.68 versus 0.33$)$. This suggests

\footnotetext{
${ }^{15}$ We should note her that Weiss and Willis measure "predicted earnings" somewhat differently.
} 
that divorce is more sensitive to the non-pecuniary dissatisfaction of the wife than to the husband's.

\section{Concluding remarks}

Our results are in line with the predictions of our theoretical background framework. Both monetary and non-monetary components of the marital output predict divorce. Moreover, they seem to combine additively in marital output. Higher subjective levels of match quality predict marriage stability. This effect is much stronger for women than for men: the marginal rate of substitution between monetary and non-monetary marital payoff is twice higher for Russian women than it is for Russian men.

The impacts of economic determinants are more complex. Higher wages for both spouses tend to reduce the divorce hazard. However, the mechanisms triggering divorce are gender-specific; the economic components destabilizing the marriage are of a different nature. We explained this in terms of men having a higher remarriage probability in the short run than women. Our investigation of the effects of expected wages also shows that high wife to husband wage ratios disrupt marriage. The finding is common in the literature; it has traditionally been attributed to the division of labor between the spouses, whereby wives take a larger part in household production while husbands invest into the labor market activity. This may be less relevant in 2010 than it was in 1980. The turnover on the marriage market is now higher; so is female labor-force participation, and matching has become more positively assortative on on wages. It may simply be that women have a higher search cost on the marriage market, and therefore are more likely to match suboptimally at first and "reoptimize" later.

Overall, our findings describe the complex pattern of an evolving marriage market. They

call for a dynamic framework allowing for frictions of the matching process on the marriage market. The RLMS data represent an excellent basis for further research in this direction since the Russian population is characterized by numerous demographic shocks experienced by various cohorts that can be exploited for identifying the matching patterns. 


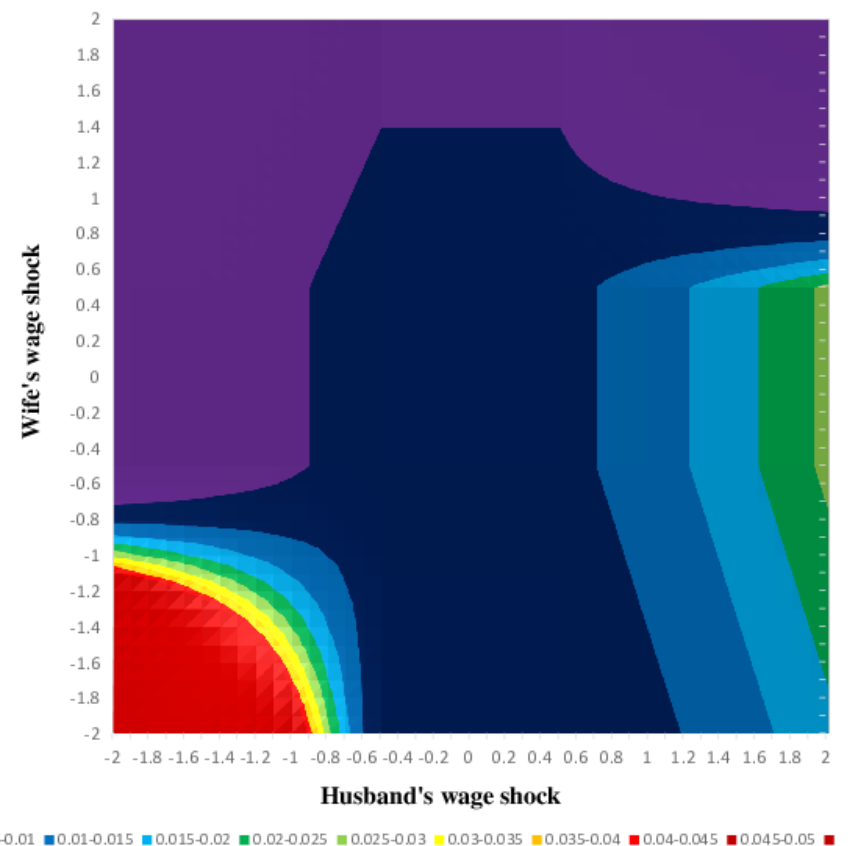

Figure 8: Divorce probability at different levels of spouses' wage shocks

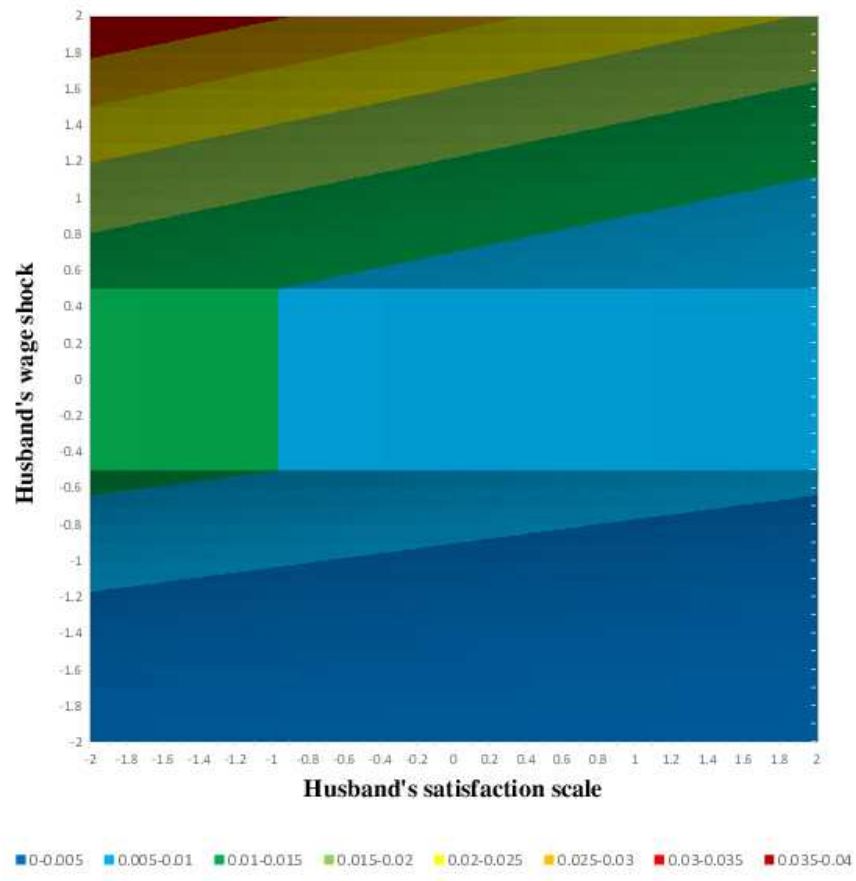

Figure 9: Divorce probability at different levels of husband's match quality and wage shock 


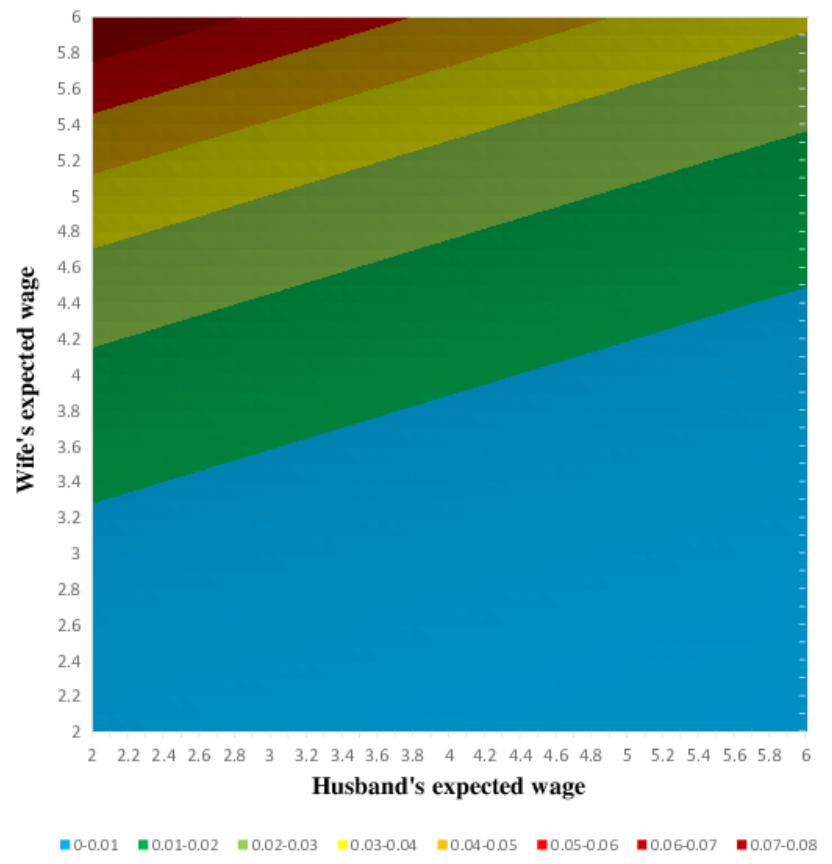

Figure 10: Divorce probability at different levels of spouses expected wage rates

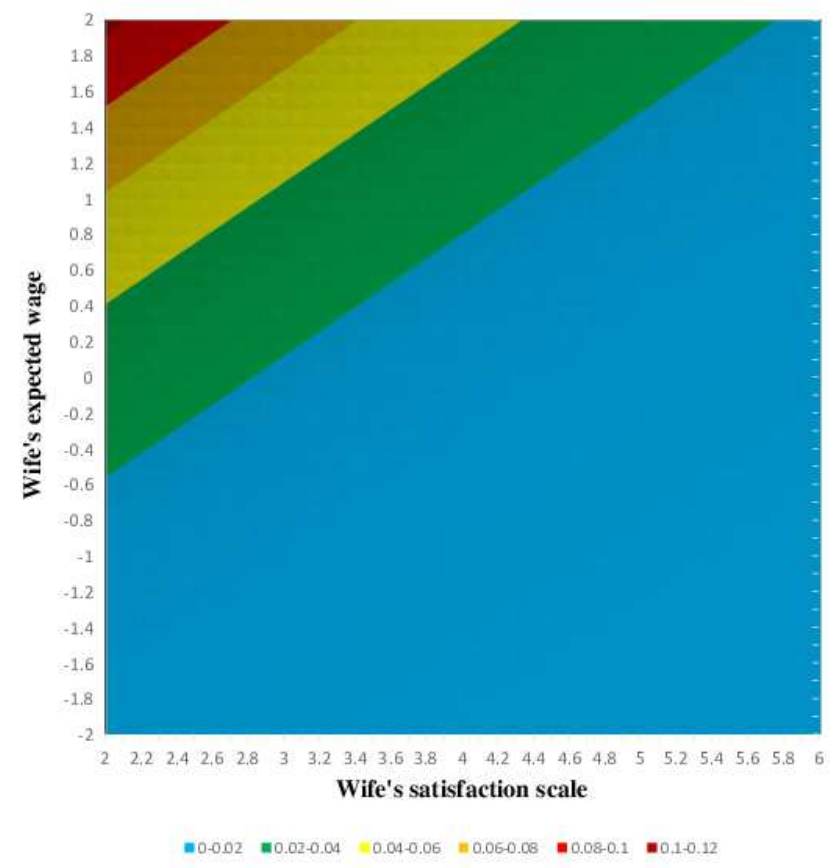

Figure 11: Divorce probability at different levels of woman's match quality and wage 


\section{References}

Battu H., Brown H. and M. Costa-Gomes (2013). "Not always for richer or poorer: The effects of income shocks and house price changes on marital dissolution," ERSA conference papers ersa13p250.

Becker G., Landes E. and R. Michael (1977). "An Economic Analysis of Marital Instability", Journal of Political Economy, 85 (6), 1141-1188.

Becker G. S. (1991). Treatise on the Family. Cambridge, MA: Harvard University Press.

Becker, G.S. (1973). "A Theory of Marriage: Part I", Journal of Political Economy, 81, 813-846.

Becker, G.S. (1974). "A Theory of Marriage: Part II", Journal of Political Economy, 82(2), S11-S26.

Blum, A., Lefevre, C., Sebille, P., Badurashvili, I., Régnier-Loilier, A., Stankuniene, V. and O. Sinyavskaya (2009). "The family anyway: France, Georgia, Lithuania, Russia", Revue d'études comparatives Est-Ouest, 40, 5-36.

Böheim R. and J. Ermisch (2001). "Partnership dissolution in the UK- the role of economic circumstances", Oxford Bulletin of Economic Statistics, 63, 197-208.

Browning M., Chiappori P.A. and Y. Weiss (2014). Economics of the Family. Cambridge Surveys of Economic Literature.

Bruze G., Svarer M. and Y. Weiss (2015). "The Dynamics of Marriage and Divorce", Journal of Labor Economics, 33 (1), 123-170.

Charles K.K. and M. Stephens (2004). "Job Displacement, Disability, and Divorce", Journal of Labor Economics, 22(2), 489-522.

Chiappori, P.A., M. Iyigun and Y. Weiss (2015). "The Becker-Coase Theorem Reconsidered", Journal of Demographic Economics, 81(2), 157-177.

Chiappori, P.A., and M. Mazzocco, "Static and Intertemporal Household Decisions", Journal of Economic Literature, forthcoming.

Chiappori, P.-A., Oreffice, S. and C. Quintana-Domeque (2012). "Fatter Attraction: Anthropometric and Socioeconomic Matching on the Marriage Market", Journal of Political Economy, 120(4), 659-695. 
Chiappori, P.A., and Y. Weiss (2006). "Divorce, Remarriage and Welfare: A General Equilibrium Approach", Journal of the European Economic Association, Papers and Proceedings, $4(2-3), 415-426$.

Chiappori, P.A., and Y. Weiss (2007). "Divorce, Remarriage, and Child Support", Journal of Labor Economics, 25(1), 37-74.

Gardner J. and A.J. Oswald (2006). "Do Divorcing Couples Become Happier By Breaking Up?", Journal of the Royal Statistical Society, 169 (2), 319-336.

Guven C., Senik C. and H. Stichnoth (2012). "You can't be happier than your wife. Happiness Gaps and Divorce", Journal of Economic Behavior \& Organization, 82 (1), 110-130.

Hess G.D. (2004). "Marriage and Consumption Insurance: What's Love Got to Do with It?", Journal of Political Economy, 112(2), 290-318.

Hoffman S. D. and G. J. Duncan (1995). "The Effect of Incomes, Wages, and AFDC Benefits on Marital Disruption", Journal of Human Resources, 30(1), 19-41.

Kalugina, E., Radchenko, N. and C. Sofer (2009a). "How Do Spouses Share their Full Income? Identification of the Sharing Rule Using Self-Reported Income", Review of Income and Wealth, 55, 360-391.

Kalugina E., Radchenko N. and C. Sofer (2009b), "Intrahousehold Inequality in Transitional Russia", Review of Economics of the Household, 7 (4), 447-471.

Lacroix G. and N. Radchenko (2011). "The Changing Intra-Household Resource Allocation in Russia", Journal of Population Economics, 24, 85-106.

Low C. (2014). "Pricing the Biological Clock: Reproductive Capital on the US Marriage Market", mimeo.

Lucas R. E., Clark A. E., Georgellis Y. and E. Diener (2003). "Reexamining adaptation and the set point model of happiness: Reactions to changes in marital status", Journal of Personality and Social Psychology, 84(3), 527-539.

Lundberg S. (2012). "Personality and marital surplus", IZA Journal of Labor Economics, $1(1), 1-21$.

Nunley J.M. and A. Seals (2010). "The Effects of Household Income Volatility on Divorce", American Journal of Economics and Sociology, Wiley Blackwell, 69(3), 983-1010. 
"Population of Russia" (2013). Higher School of Economics \& Demography Institute. Annual report, in Russian.

Radchenko, N. (2015). "Welfare Sharing Within Households: Identification from Subjective Well-being Data and the Collective Model of Labor Supply", Journal of Family and Economic Issues, 36(1).

Rainer H. and I. Smith (2010). "Staying together for the sake of the home?: house price shocks and partnership dissolution in the UK", Journal of the Royal Statistical Society, $173(3), 557-574$.

"Russia in Figures". Russian Federal State Statistics Service, http://www .gks .ru/wps/wcm/ connect/rosstat_main/rosstat/ru/statistics/population/demography/.

van Der Klaauw, W. (1996). "Female Labor Supply and Marital Status Decisions: A LifeCycle Model", Review of Economic Studies, 63(2), 199-235.

Van Praag B.M.S.(2007). "Perspectives from the Happiness Literature and the Role of New Instruments for Policy Analysis", IZA Discussion Paper, N 2568.

Waite L. and M. Gallagher (2000). "The Case for Marriage", New York: Doubleday.

Weiss Y. and R.J. Willis (1997). "Match Quality, New Information, and Marital Dissolution", Journal of Labor Economics, 15(2), 293-312. 


\section{A Appendix}

\begin{tabular}{|c|c|c|c|c|c|}
\hline & Wives & Husbands & Divorced $^{\text {a) }}$ & Women & Divorced $^{\text {a) }}$ Men \\
\hline \multicolumn{6}{|l|}{ Individual characteristics } \\
\hline \multirow[t]{2}{*}{ Age } & 41 & 43 & 37 & & 41 \\
\hline & $(10)$ & $(10)$ & (9) & & (9) \\
\hline \multirow[t]{2}{*}{ Number of children } & 1.2 & 1.2 & 1.4 & & 1 \\
\hline & $(0.8)$ & $(0.8)$ & $(0.9)$ & & $(0.9)$ \\
\hline \multirow[t]{2}{*}{ Years of education } & 13 & 13 & 13 & & 12 \\
\hline & $(3)$ & $(3)$ & $(3)$ & & $(2)$ \\
\hline \multirow[t]{2}{*}{ Wage $(\ln )$} & 3.7 & 4 & 4.2 & & 4.5 \\
\hline & $(1.4)$ & $(1.4)$ & $(1.2)$ & & $(1.1)$ \\
\hline \multicolumn{6}{|l|}{ Subjective data } \\
\hline \multirow[t]{2}{*}{ Satisfaction with life ${ }^{\mathrm{b})}$} & 3 & 3 & 3 & & 3 \\
\hline & (1) & (1) & (1) & & (1) \\
\hline \multirow[t]{2}{*}{ Satisfaction with economic conditions $\left.{ }^{b}\right)$} & 3.6 & 3.6 & 3.6 & & 3.8 \\
\hline & (1) & (1) & (1) & & (1) \\
\hline \multirow[t]{2}{*}{ Economic $\operatorname{rank}^{\mathrm{c})}$} & 4 & 4 & 4 & & 4 \\
\hline & $(1.3)$ & $(1.3)$ & (1) & & $(1.4)$ \\
\hline Health evaluation ${ }^{\mathrm{d})}$ & 2.7 & 2.6 & 2.6 & & 2.7 \\
\hline \multicolumn{6}{|l|}{ Region of residence } \\
\hline Moscow - St-Petersburg & \multicolumn{2}{|r|}{0.10} & \multicolumn{3}{|c|}{0.11} \\
\hline North / Northeastern & \multicolumn{2}{|r|}{0.06} & \multicolumn{3}{|c|}{0.08} \\
\hline Central / Black sea & \multicolumn{2}{|r|}{0.22} & \multicolumn{3}{|c|}{0.23} \\
\hline Volga / Viatsk / Volga basin & \multicolumn{2}{|r|}{0.20} & \multicolumn{3}{|c|}{0.20} \\
\hline North Caucus & \multicolumn{2}{|r|}{0.11} & \multicolumn{3}{|c|}{0.14} \\
\hline Ural & \multicolumn{2}{|r|}{0.18} & \multicolumn{3}{|c|}{0.14} \\
\hline Western Siberia & \multicolumn{2}{|r|}{0.06} & \multicolumn{3}{|c|}{0.04} \\
\hline Eastern Siberia & \multicolumn{2}{|r|}{0.07} & \multicolumn{3}{|c|}{0.06} \\
\hline
\end{tabular}

a) Divorced here denotes those who divorced over the course of the panel

b) 1:strongly satisfied;...5: not at all satisfied

c) $1:$ poor;... 9: rich

d) 1: very good; ...5: very bad

Standard errors in parentheses.

Table A.1: Descriptive statistics on the key variables 


\begin{tabular}{|l|c|}
\hline Covariate & Estimate \\
\hline$<3$ years marriage duration $\times$ husband's wage $(\ln )$ & $.232^{* * *}$ \\
3-4 years marriage duration $\times$ husband's wage $(\ln )$ & $(.014)$ \\
& $.222^{* * *}$ \\
& $(.013)$ \\
5-8 year marriage duration $\times$ husband's wage $(\ln )$ & $.215^{* * *}$ \\
& $(.013)$ \\
9-13 year marriage duration $\times$ husband's wage $(\ln )$ & $.215^{* * *}$ \\
& $(.012)$ \\
14-18 year marriage duration $\times$ husband's wage $(\ln )$ & $.203^{* * *}$ \\
& $(.012)$ \\
19-23 year marriage duration $\times$ husband's wage $(\ln )$ & $.198^{* * *}$ \\
& $(.012)$ \\
24-29 year marriage duration $\times$ husband's wage $(\ln )$ & $.184^{* * *}$ \\
& $(.013)$ \\
30-34 year marriage duration $\times$ husband's wage $(\ln )$ & $.175^{* * *}$ \\
& $(.014)$ \\
35-41 year marriage duration $\times$ husband's wage $(\ln )$ & $.181^{* * *}$ \\
& $(.020)$ \\
Age & $.010^{* * *}$ \\
& $(.002)$ \\
Years of education & $.056^{* * *}$ \\
& $(.004)$ \\
Year dummies & $Y e s$ \\
Regional dummies & $Y e s$ \\
Constant & $2.5^{* * *}$ \\
& $(.108)$ \\
\hline$N$ & 6794 \\
\hline Sta
\end{tabular}

Standard errors in parentheses. ${ }^{* * *} p<0.01,{ }^{* *} p<0.05,{ }^{*} p<0.1$

Table A.2: Assortative matching: regressing log female wages 


\begin{tabular}{|c|c|c|c|}
\hline \multicolumn{2}{|l|}{ Monetary determinants } & \multicolumn{2}{|l|}{ Non monetary determinants } \\
\hline Husband's wage shock & $\begin{array}{l}-.056 \\
(.107)\end{array}$ & Wife's $\left.\theta^{c}\right)$ & $\begin{array}{r}-.214^{* * *} \\
(.037)\end{array}$ \\
\hline Husband's strong positive wage shock ${ }^{\mathrm{a})}$ & $\begin{array}{l}.399 \\
(.262)\end{array}$ & Husband's $\theta$ & $\begin{array}{l}-.062^{*} \\
(.036)\end{array}$ \\
\hline Husband's strong negative wage shock ${ }^{\mathrm{b}}$ ) & $.573^{* *}$ & & \\
\hline Wife's wage shock & $\begin{array}{c}(.285) \\
.013 \\
(.111)\end{array}$ & $\begin{array}{l}\text { Husband's years of education } \\
\text { Wife's minus husband's education }\end{array}$ & $\begin{array}{c}-.037^{* *} \\
(.018) \\
.016\end{array}$ \\
\hline Wife's strong positive wage shock ${ }^{\mathrm{a}}$ ) & $\begin{array}{l}-.233 \\
(.289)\end{array}$ & & $(.012)$ \\
\hline Wife's strong negative wage shock ${ }^{\mathrm{b}}$ ) & $\begin{array}{l}.078 \\
(.321)\end{array}$ & Husband's age & $\begin{array}{l}-.001 \\
(.004)\end{array}$ \\
\hline $\begin{array}{l}\text { Wife's strong positive wage shock } \\
\times \text { husband's strong positive wage shock }\end{array}$ & $\begin{array}{l}-.869 \\
(.892)\end{array}$ & Wife's minus husband's age & $\begin{array}{l}-.013 \\
(.009)\end{array}$ \\
\hline $\begin{array}{l}\text { Wife's strong negative wage shock } \\
\times \text { husband's strong negative wage shock }\end{array}$ & $\begin{array}{c}1.666^{* *} \\
(.827)\end{array}$ & Number of children & $-.068^{*}$ \\
\hline Wife's unemployment episode & $\begin{array}{l}.282^{* *} \\
(.141)\end{array}$ & & $(.041)$ \\
\hline Husband's unemployment episode & $\begin{array}{l}.062 \\
(.116)\end{array}$ & & \\
\hline Joint unemployment episodes & $\begin{array}{c}.756^{* * *} \\
(.188)\end{array}$ & & \\
\hline Expected wife's wage & $\begin{array}{l}.316^{* * *} \\
(.086)\end{array}$ & Regional dummies & Yes \\
\hline Expected husband's wage & $\begin{array}{l}-.096 \\
(.085)\end{array}$ & Year dummies & Yes \\
\hline Within group correlation & $\begin{array}{l}.774^{* * *} \\
(.016)\end{array}$ & Constant & $\begin{array}{c}-3.44^{* * *} \\
(.552)\end{array}$ \\
\hline$N$ & 15843 & & \\
\hline
\end{tabular}

a) $10 \%$ right tail

b) $10 \%$ left tail

c) $\theta$ corresponds to the theoretical $\theta$ : the higher one's $\theta$, the higher one's benefit to marriage Standard errors in parentheses. ${ }^{* * *} p<0.01,{ }^{* *} p<0.05,{ }^{*} p<0.1$

Table A.3: Transitions to divorce status (random effects probit estimates) 